\title{
Active tectonics of the Black Sea with GPS
}

\author{
Ergin Tari ${ }^{1}$, Muhammed Sahin ${ }^{1}$, Aykut Barka ${ }^{2}$, Robert Reilinger ${ }^{3}$, Robert W. King ${ }^{3}$, Simon McClusky ${ }^{3}$, and M. Prilepin ${ }^{4}$ \\ ${ }^{1}$ Department of Geodesy and Photogrammetry, Istanbul Technical University, 80626 Maslak, Istanbul, Turkey \\ ${ }^{2}$ Eurasian Institute of Earth Sciences, Istanbul Technical University, 80626 Maslak, Istanbul, Turkey \\ ${ }^{3}$ Department of Earth, Atmospheric, and Planetary Sciences, MIT, Cambridge 02139, U.S.A. \\ ${ }^{4}$ Joint Institute of Physics of the Earth, Moscow 123810, Russia
}

(Received December 25, 1999; Revised June 30, 2000; Accepted July 6, 2000)

\begin{abstract}
The Black Sea occurs within the Anatolian sector of the Alpine-Himalayan orogenic system. In this region northward moving African and Arabian plates collide with Eurasian plate. From this collision the Anatolian block moves westward with a rotation pole located approximately north of Sinai peninsula. Tectonic styles and rates in the circum Black Sea and along the Crimea have been poorly known. A GPS project was initiated in 1995 with the collaboration between Istanbul Technical University, MIT and Joint Institute of Physics of the Earth (Moscow). To carry out the project, two GPS campaigns were performed. Data have been analysed by the well-known GPS processing program, GAMIT which is a comprehensive GPS analysis package, and GLOBK, a Kalman filter. This paper presents the important outputs from the two GPS campaigns and gives suggestions for the future investigations in the region. The important outcome of the project is that the N-S motions along mostly in the Eastern margin of the Black Sea are in a few mm/year, such as SINO, a southern coast site, with a rate of $1.4 \pm 1.7 \mathrm{~mm} / \mathrm{year}$ in NW direction, and GELE, a northern coast site, with a rate of $2.2 \pm 2.8 \mathrm{~mm} /$ year in SE direction, while the velocities in the Anatolian region are approximately $10-20 \pm 3-5 \mathrm{~mm} /$ year.
\end{abstract}

\section{Introduction}

The Black Sea is one of the largest enclosed seas and has been in existence for the last 200 Ma. The Black Sea occurs within the Anatolian sector of the Alpine-Himalayan orogenic system and it is located between the Eurasian plate in the north and the African-Arabian plates in the south. Global plate models (DeMets et al., 1990; DeMets et al., 1994) and recent space geodetic measurements (Smith et al., 1994; Reilinger et al., 1997a) indicate that in the surrounding region northward moving the African and the Arabian plates collide with the Eurasian plate. From this collision the Anatolian block moves westward with a rotation pole located approximately in the north of the Sinai peninsula. Within this tectonic framework, the present-day tectonics of the Black Sea has been a puzzle.

The Global Positioning System (GPS) has become a very useful tool in the area of earth sciences because of its capability that provides high precision assessment of continental and regional deformation (Segall and Davis, 1997; Herring, 1999; Tari, 1999). In this paper, GPS observations collected in the Black Sea's surrounding area are taken into consideration in order to have information about the contemporary tectonic processes of the region.

\section{Tectonic History}

Geologically the Black Sea basin is divided into two parts, Western and Eastern, separated by the Mid Black Sea ridge (Figs. 1 and 2). The origin of the Black Sea has been long

Copy right (c) The Society of Geomagnetism and Earth, Planetary and Space Sciences (SGEPSS); The Seismological Society of Japan; The Volcanological Society of Japan; The Geodetic Society of Japan; The Japanese Society for Planetary Sciences. studied and is complicated in detail. The rifting age has been suggested as the Aptian-Albian period for the entire Black Sea (Gorur, 1997), nevertheless rifting age for the Eastern Black is less known (Spadini et al., 1996). Following the closure of the Neothys the Black Sea began also to close in the Eocene-Oligocene time. The eastern Black Sea continued to close from Miocene up to present. On the other hand, the central and western Black Sea has more complicated neotectonics influenced by all, escape of the Anatolian block, northward motion of the African plate and the Aegean extension.

Seismic activity within the circum Black Sea is assumed as low-moderate for this century. The western end of the Black Sea, north of the Marmara Sea, Bulgaria, Romania and Ukraine should be influenced by extensional tectonics in the Western Turkey and Aegean. There is a speculation that the lithosphere of the Black Sea and Caspian Seas form a resistant "backstop" diverting the impinging Anatolian plate to the west and "funneling" the continental lithosphere of eastern Turkey and the Caucasus around the eastern side of the Black Sea (McClusky et al., 2000).

\section{Black Sea GPS Campaigns}

GPS measurements in the Black Sea region were collected as parts of different projects, some of which are still in progress (McClusky et al., 2000; Tari, 1999). As part of these projects eastern and western Turkey were observed between 1988 and 1992 with sufficient overlap to allow integration of networks, but since the 1994 survey almost all of the stations were occupied during each survey (Reilinger et al., 1997b; Tari, 1999). Although some of sites in Bul- 


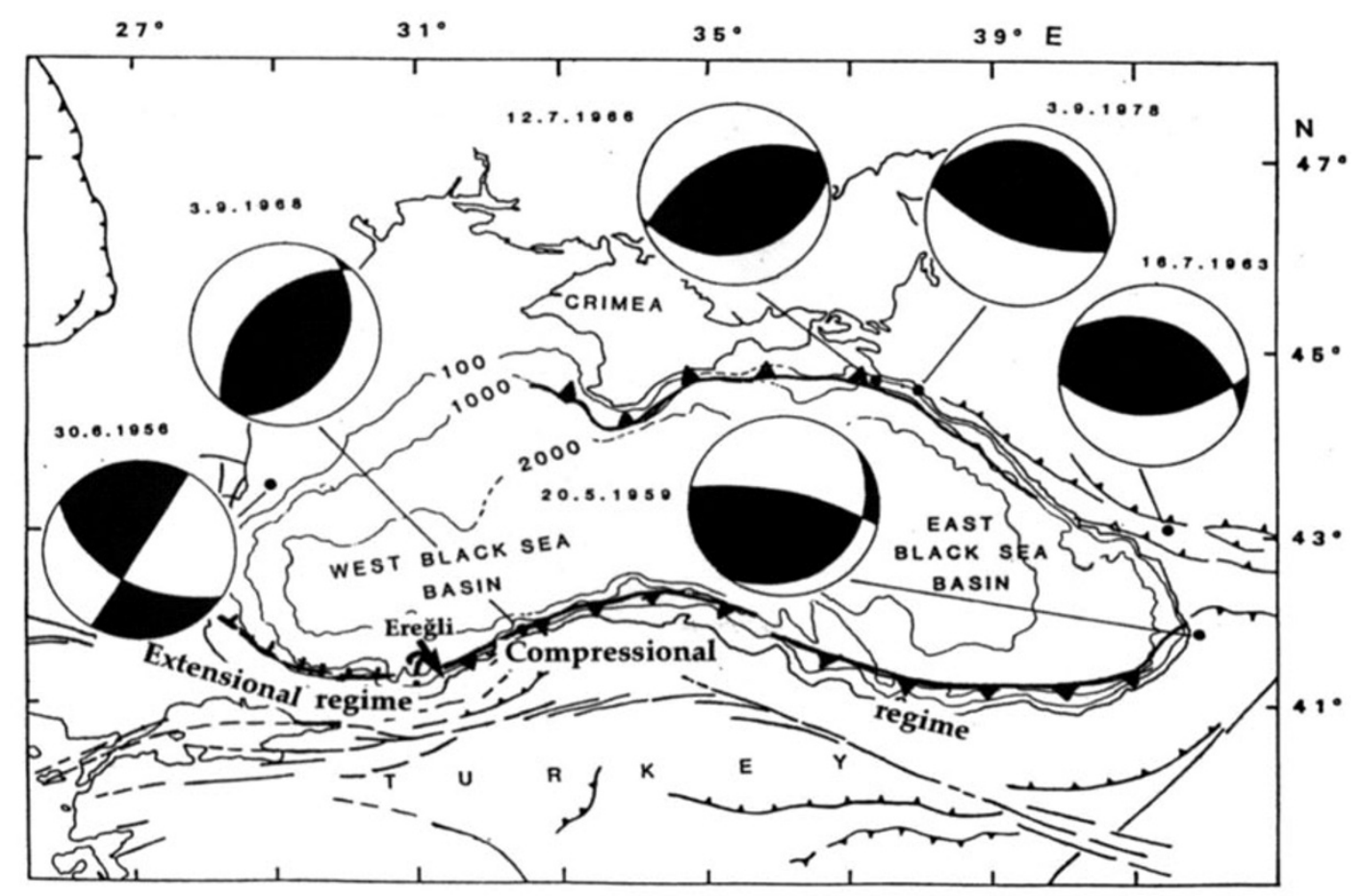

Fig. 1. Tectonics of the Black Sea (from Barka and Reilinger, 1997). Most of the southern and northern margins show shortening, except north of the Marmara Sea region (west of the $31^{\circ} \mathrm{E}$ ) and Bulgarian and Romanian coasts which are in the extensional nature.

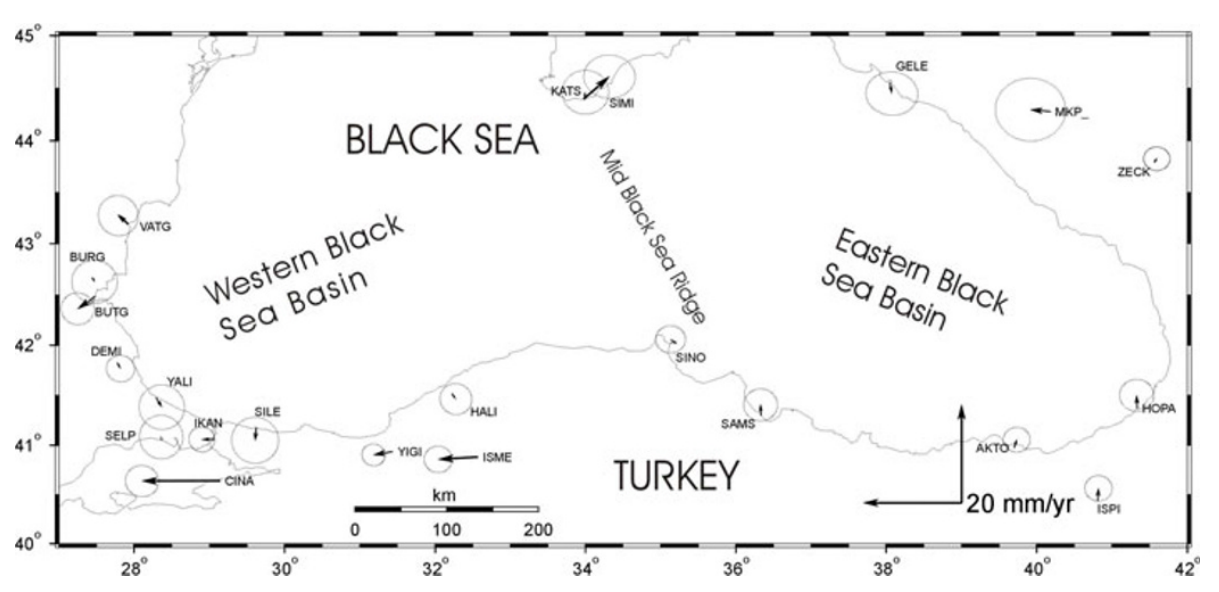

Fig. 2. GPS velocities with respect to Eurasian frame.

garia were observed in 1994 and 1996, most of the network in Bulgaria was observed in 1996 and 1998. Additionally a network in the Caucasus was observed in 1991, 1994, 1996 and 1998 (Table 1) (Reilinger et al., 1997a; Tari, 1999).

\section{Black Sea GPS Data Analysis}

The GPS data processing has been performed at mainly MIT and partly at ITU by using GAMIT/GLOBK software (Herring, 1998; King and Bock, 1998) in a three-step approach described in Feigl et al. (1993) and Dong et al. (1998). In the first step, doubly differenced GPS phase observations from each day were used to estimate station coordinates, the zenith delay and the gradients of the atmosphere at each station, and orbital and Earth orientation parameters (EOPs) by applying loose a priori constraints to all parameters. In general, 3 or 4 IGS stations are included within this analysis as long as they exist. Hence, the link between regional and global networks is established. Using 3 or 4 global sites in the regional analysis provides enough overlap to resolve the parameters. For initial conditions and non-gravitational parameters for each GPS satellites at a specific time, files from SOPAC are used as well as the ones are computed at MIT for earlier experiments.

In the second step, the loosely constrained estimates of station coordinates, orbits, EOPs and their covariances from each day, formed by survey, were used as quasi-observations in a Kalman filter to estimate a consistent set of coordinates and velocities for a group of survey, which represented 


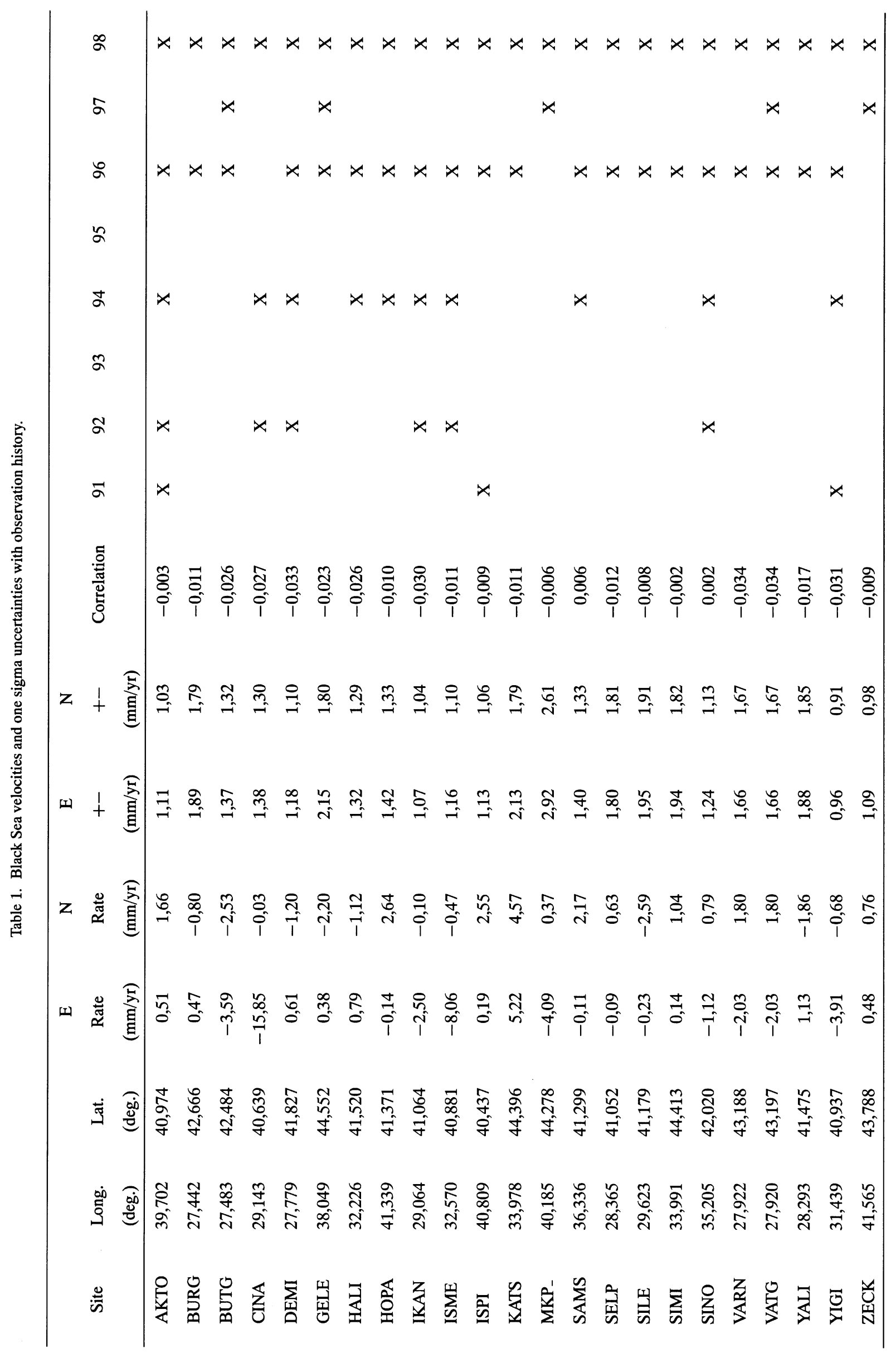


as yearly combination of the relevant experiment set. The global analysis of IGS data are also used as quasi observations. The weights for each data set of quasi-observations are determined by averaging the increments in chi-square per degree of freedom from a forward and backward filtering of data (McClusky et al., 2000).

The reference frame for velocity estimates was defined only at the third step, in which generalized constraints were applied while estimating a 6-parameter transformation (6 components of the rate of change of translation and rotation). Specifically, the departure of the horizontal velocities of 16 stations, from their a priori values given by the International Terrestrial Reference Frame 1996 (ITRF96), was minimized to define a realization of Eurasian Frame (Boucher et al., 1998; McClusky et al., 2000). The root mean square (rms) departure of the velocities of the 16 stations after the transformation was $0.5 \mathrm{~mm} / \mathrm{yr}$. The estimated velocities were then rotated from no-net-rotation frame of ITRF96 to the Eurasiafixed frame defined in this research using NUVEL-1A Euler vectors (Table 1) (DeMets et al., 1994; Tari, 1999). The onesigma uncertainties for the GPS velocities were derived by scaling the formal errors by the square root of chi-square per degree of freedom of the solution. The chi-square per degree of freedom for this solution was 1.07. Velocities of stations with respect to the Eurasian frame are shown in Fig. 2 in which $95 \%$ confidence regions are plotted.

\section{Conclusions}

Velocities show that there is a slight north-south shortening on the eastern half of southern the Black Sea coast, whereas a westward movement can be seen regarding the southwestern coast. However, the magnitudes of the velocity vectors compared with the size of the error ellipses indicate the necessity for further GPS measurements in the region for further confirmation. For example, the magnitudes and directions of KATS and MKP_ sites show that there are some uncertainties related with velocity rate parameters, although it is known that the rates around Caucasus are assumed to vary considerably (Reilinger et al., 1997a). Another outcome is that the North-South motions mostly in the eastern Black Sea are in a few $\mathrm{mm} /$ year, while the velocities in the Anatolian region are approximately $10-20 \mathrm{~mm} /$ year.

Geological and geophysical evidence including offshore seismic reflection profiles (Finetti et al., 1988), offshore morphology (Meisner et al., 1995), onshore geology and morphology (Okay and Sahinturk, 1997 and references therein), and recent seismic activity (Neprochnov and Ross, 1978; Barka and Reilinger, 1997) support the idea that the compressional tectonic regime is still active in the Eastern Black Sea region. In addition, fault plane solutions of May 20, 1959 , July 16 , 1963 , July 12,1966 , September 3, 1968, and September 3, 1978 earthquakes (Fig. 1) clearly indicate a compressional tectonic regime.

South-west part of the Black Sea do not show important seismic activity to decide whether compressional or tensional regime is active. Although fault plane solution of 30.6.1956 earthquake indicate an extensional regime, this is probably related with the Sredna Gora Graben in the Bulgarian coast. GPS results from this part are scattered and are not enough to state any conclusion for the regional tectonics. More GPS and seismic data will clarify the neotectonic position of this region.

There are uncertainties at the sites located in the northern part of the Black Sea due to the lack of observations. On the other hand, there are no sites in the northern-west part of the region and around the Crimea. More sites and more observation periods will ensure us to resolve the uncertainties and the tectonic behaviour of the whole region.

Acknowledgments. Figure 2 was generated using the Generic Mapping Tools software (Wessel and Smith, 1995). The authors would like to thank to T. Herring and N. Toksoz for their supports. Valuable advices from $\mathrm{O}$. Tuysuz are also grateful. The concrete and helpful suggestions by Kosuke Heki and an anonymous reviewer are very appreciated. E. Tari's visit to MIT was funded by the Turkish Scientific and Technical Research Council (TUBITAK) and Istanbul Technical University (ITU). The "Black Sea Tectonics with GPS" project is supported by the ITU and TUBITAK.

\section{References}

Barka, A. and R. Reilinger, Active Tectonics of Eastern Mediterranean region: deduced from GPS, neotectonic and seismicity data, Annali $D i$ Geofisica, X2(3), 587-610, 1997.

Boucher, C., Z. Altamimi, and P. Sillard, Results and Analysis of the ITRF96, IERS Technical Note 24, 166 pp., Cebtral Beureau of IERSObservatoire de Paris, 61 Avenue de l'Observatoire, F-75014, Paris, France, 1998 .

DeMets, C., R. G. Gordon, D. F. Argus, and S. Stein, Current plate techtonics, Geophys. J. Int., 101, 425-478, 1990.

DeMets, C., R. G. Gordon, D. F. Argus, and S. Stein, Effects of recent revisions to the geomagnetic reversal time scale on estimates of current plate motions, Geophys. Res. Lett., 21, 2191-2914, 1994.

Dong, D.-N., T. A. Herring, and R. W. King, Estimating regional deformation from a combination of space and terrestrial geodetic data, J. Geod., 72, 200-214, 1998.

Feigl, K. L, D. C. Agnew, Y. Bock, D.-N. Dong, A. Donnellan, B. H. Hager, T. A. Herring, D. D. Jackson, R. W. King, S. K. Larsen, K. M. Larson, M. H. Murray, and Z.-K. Shen, Measurement of the velocity field in central and southern California, J. Geophys. Res., 98, 21667-21712, 1993.

Finetti, I., G. Bricchi, A. Del Ben, M. Pipan, and Z. Xuan, Geophysical study of the Black Sea Area, Bollettino di Geofisica Teorica e Applicata, 30(117-118), 197-324, 1988.

Gorur, N., Crateceous syn- to postrift sedimantation on the Southern Continental Margin of the Western Black Sea Basin, in Regional and Petroleum Geology of the Black Sea and Surrounding Region, edited by A. G. Robinson, American Association of Petroleum Geologists (AAPG), AAPG Memoir 68, pp. 227-240, 1997.

Herring, T. A., GLOBK: Global Kalman filter VLBI and GPS analysis program Version 4.1 Internal Memorandum, Massachusetts Institute of Technology, Cambridge, 1998.

Herring, T. A., Geodetic applications of GPS, Proceedings of the IEEE, 87, 92-110, 1999.

King, R. W. and Y. Bock, Documentation for the GAMIT analysis software, release 9.7, Massachusetts Institute of Technology, Cambridge, MA, 1998.

McClusky, S., S. Balassania, A. Barka, C. Demir, S. Ergintav, I. Georgiev, O. Gurkan, M. Hamburger, K. Hurst, H. Kahle, L. Kastens, G. Kekelidze, R. W. King, V. Kotzev, O. Lenk, S. Mahmoud, A. Mishin, M. Nadariya, A. Ouzounis, D. Paradissis, Y. Peter, M. Prilepin, R. Reilinger, I. Sanli, H. Seeger, A. Taeleb, M. N. Toksoz, and G. Veis, GPS constraints on plate motions and deformation in the Eastern Mediterranean: Implications for plate dynamics, J. Geophys. Res., 105, 5695-5719, 2000.

Meisner, L. B., A. S. Gorshkoz, and D. A. Tugolesov, Neogene-quaternary Sedimantation in the Black Sea Basin, in Geology of the Black Sea Basin, edited by A. Erler, T. Ercan, E. Bingöl, and S. Örçen, pp. 131-136, General Directorate of Min. Res. And Explor. Ankara, 1995.

Neprochnov, Y. P. and D. A. Ross, Black Sea geophysical framework, in Initial Reports of the Deep Sea Drilling Project 42, Part 2, edited by J. L. Usher and P. Supko, pp. 1043-1055, 1978.

Okay, A. I. and O. Sahinturk, Geology of the Eastern Pontides, in Regional and Petroleum Geology of the Black Sea and Surrounding Region, edited by A. G. Robinson, pp. 291-311, American Association of Petroleum 
Geologists (AAPG), AAPG Memoir 68, 1997.

Reilinger, R. E., S. C. McClusky, and B. J. Souter, Preliminary estimates of plate convergence in the Caucasus collision zone from GPS measurements, Geophys. Res. Lett., 24, 1815-1818, 1997a.

Reilinger, R. E., S. C. McClusky, and M. B. Oral, GPS measurements of present day crustal movements in the Arabia-Africa-Eurasia plate collision zone, J. Geophys. Res., 102, 9983-9999, 1997b.

Segall, P. and J. L. Davis, GPS application for geodynamics and earthquake studies, Annu. Rev. Earth Planet. Sci., 25, 301-336, 1997.

Smith, D. E., R. Kolenkiewics, J. W. Robbins, P. J. Dunn, and M. H. Torrence, Horizontal crustal motion in the central and eastern mediterranean inferred from satellite laser ranging measurements, Geophys. Res.
Lett., 21, 1979-1982, 1994.

Spadini, G., A. Robinson, and S. Cloetingh, Western versus Eastern Black Sea tectonic evolution: Pre-rift lithospheric controls on basin formation, Tectonophys., 266(1-4), 139-154, 1996.

Tari, E., 1st and 2nd Progress Reports submitted to TUBITAK and ITU about the post doctoral research at MIT, 1999 (unpublished).

Wessel, P. and W. H. F. Smith, New version of the generic mapping tools released, EOS Trans. $A G U, \mathbf{7 6}, 329,1995$.

E. Tari, M. Sahin (e-mail: sahin@itu.edu.tr), A. Barka, R. Reilinger, R. W. King, S. McClusky, and M. Prilepin 